\title{
Loading and Haulage Equipment Selection for Optimum Production in a Granite Quarry
}

\begin{abstract}
A. O. Owolabi*
Nigeria

*Corresponding Author: A. O. Owolabi, Nigeria

Abstract: The appropriate selection of suitable fleet of equipment and their application could minimize the capital and operational costs. One of the major costs in mine is related to the purchase and application of equipment. Proper fleet selection, in a way that secures the production needs of a mine as well as minimizing the cost of production, is one of the main challenges of mine planners. The equipment selection process can be classified into three phases i.e. type of fleet, size of equipment, and calculation of required numbers. This study focuses on the proper equipment selection that optimizes production efficiency, and meets the desired output from the available working-time which can also be referred to as the time factor. This is achieved by helping in the determination of a satisfactory cycle time that will conform with the continuous functioning of the loader, which leads to the design of a fleet system that will be perfect for a shovel from the inequality $C Y T_{M I N} \leq N T(T l+T s)$. This implies that the circle time must be less than or equal to the number of trucks multiplied by the summation of the loading time and the spotting time. This also means that the loader should at no time during the loading and haulage operation await other trucks, unless there is a problem at the crushing unit. The optimal determination of the number of trucks that will be effective for the continuous operation of any selected excavator to yield the desired output of the company forms the basis of this research.
\end{abstract}

\section{INTRODUCTION}

The equipment selection process begins at the conception of mine development. In many industries, materials handling represents a significant component of the operational cost, making equipment selection a major challenge to management.

Lizotte [1] affirmed that equipment selection affects economic considerations in open-pit design, particularly showing overburden, waste rock and ore mining costs and cost escalation parameters as a function of plan location and depth. Mining costs are a function of site conditions, operating scale and equipment. The purpose of equipment selection is to select equipment that can operate optimally.

Equipment selection is one of the most important aspects of open pit design. Mining costis mainly affected by the number and capacity of equipment. Equipment selection for open-pit mines is a major decision, which in turn, impacts greatly on the economic viability of an operation [2].Models for equipment selection and evaluation described by Celebi [3] were aimed at selection of the equipment fleet on the basis of minimizing the unit stripping cost and maximizing production.

Mining trucks, also referred to as haul trucks or road trucks, are used to haul (transport) the ore or waste material from the loader to the dumpsite. In most cases, these vary from 36 tons to 315 tons. The size and cost of operating mining trucks are directly proportional to its tray capacity, while the speed at which the truck can travel is inversely proportional to its capacity. As with loaders, the variety of truck types differs according to their reliability, maintenance requirements, productivity and operating cost. The mine environment greatly affects the performance of a truck. For example, "rimpull" affects the forward motion of the truck. Rimpull is the natural resistance of the ground to the torque of the tyre, and is equal to the product of the torque of the wheel axle and the wheel radius. Manufacturers supply pre-determined rimpull curves for their trucks to enable a satisfactory calculation of truck cycle times. The rimpull curves delineate the increase in road resistance as the truck increases speed [4].

Also, the softness of the road soil creates an effect of rolling resistance (against the truck tyres) that reduces the efficiency of the truck in propelling itself forward. Rolling resistance varies significantly 
across the road and over time, and is very difficult to estimate. Watering and compressing the roads regularly can control and reduce the effects of rolling resistance. Haul grade, which is the incline of the haul road, can exacerbate the effects of rolling resistance and rimpull. These parameters, in addition to distance travelled, are crucial for the accurate calculation of the truck cycle time [5].

The type of loader selected for use in a surface mine depends on the type of mineral to be extracted and specifications of the environment, such as the bench height. We must also consider other factors in the equipment selection process, particularly, the compatibility of the loaders with selected truck fleets. For example, some loaders cannot reach the top of the tray on the larger trucks. Conversely, some loader's capacity exceeds the capacity of the truck. If we are to determine the best truck and loader set, then we must model the problem such that we select the truck and loader types simultaneously [6].

The loading and hauling machines choice are made based on the deposit characteristics and geometry of loaders or shovel and trucks. Selection of both loaders or shovels and trucks begins with loaders or shovel; this is because trucks performance is influenced more by the loaders choice than vice versa. Specific availability and utilization data for loaders or shovel and haulage trucks depends on calculation methods and operating maintenance practices used in aparticular situation. The number and size of hauling unit (trucks) to loading unit (wheel loaders and hydraulic shovels) need to properly match in order to provide the best possible fleet match [7].

The combined task of loading and haulage are the fundamental in the mining industry. In the simplest scenario, a loading device is used to load fragmented rocks (run-off mine) into a conveying unit, which carries the mine run-off to where it will be beneficiated. In addition to the loading and haulage of the actual valuable mineral commodity being exploited, many mine operations require loading and haulage of large volume of overburden to expose the economically viable deposit. Although, some loading and haulage operations such as disposal of mill tailings or replacement of topsoil at strip mines are ancillary to the actual production cycle the same principles are applied [8].

Generally speaking, the material most commonly handled in the mining industry are rocks that have been fragmented either by mechanical or explosive methods. These rocks can be ores containing economic materials, they can be saleable mineral products in a fairly undiluted form such as coal, phosphate and industrial minerals, or they can be waste rocks that must be excavated to expose the economic mineral deposits. Some of the physical properties that affect the handling of materials are abrasion, adhesion, cohesion, angle of repose, compressibility, bulk density, fragment size, fragment shape and void ratio. Fragment size is determined primarily by the method of fragmentation. Although any material will have some in-situ moisture content, this property may be altered during the materials handling process. The remainder of the properties listed is inherent to specific minerals handling system [8].

\section{FundaMental Terms}

1. Production: Total volume or weight of material to be handled in a specific operation. It can refer to either the economic mineral to be produced or the waste minerals. Mineral production is given most frequently in units of weight while waste rock is often expressed in units of volume. It is common, for example, to refer to total annual production.

2. Production Rate: The theoretical production volume or weight of a machine per unit of time. It is usually expressed on an hourly basis but can be given for other units of time such as shift or a day.

3. Productivity: The actual production per unit time when all the efficiency and other management factors are considered. It can also be referred to as a net production rate, or production per unit of labour and time (e.g., tons/employee-shift).

4. Efficiency: The percentage of estimated production rate that is actually handled by a machine. Reduction in production rate can be related to the machine itself, personnel, or job condition. The efficiency factor can be as the average number of minutes worked as full production in one hour divided by 60 minutes

5. Availability: that portion of a scheduled producing time that a machine is mechanically ready to work

6. Utility: That portion of the available time that a machine is actually working.

7. Capacity: refers to the volume of a material that a loading or haulage unit can hold at any point in time (e.g., volume of a loading machine bucket or a truck bed). 


\subsection{Factors for Consideration in Equipment Selection}

Four groups of factors largely determine the selection of excavating equipment (the discussion applies specifically to surface equipment but the factor are applicable to underground as well) [9].

1. Performance factor: This relates to machine productivity, and includes cycle speed available force (power), digging range bucket capacity, travel speed and reliability.

2. Design factor: The design factor provides insight into the quality and effectiveness of detail design, including the sophistication of human-machine interface for operators and maintenance personnel, the level of technology employed and the kind of control and power available.

3. Support Factor: Sometimes overlooked in machine evaluation, support factors are reflected in servicing and maintenance. Ease for servicing, special skills involved, parts availability and manufacturer's support are important considerations.

4. Cost Factor: Probably the most quantitative (and ultimate) factor, costs are determined by standard estimating procedures for large mining and construction equipment. If reasonable assumption as to life interest rate, inflation, fuel and maintenance are made then results should be meaningful. The customary basis is to use unit costs all computed on an $\mathrm{s} / \mathrm{hr}$. and converted to s/ton (s/ton) or s/yd ${ }^{3}$ $\left(\mathrm{s} / \mathrm{m}^{3}\right)$.

\subsection{Selection of Loading and Haulage Equipment}

\subsubsection{Calculations for selection of Shovel Excavator (Loading and Haulage Equipment)}

Practical consideration of the following three factors is important in choosing the right size of a shovel or any single -bucket excavator:

$>$ Time factor

Operational factor

Bucket fill factor

\subsubsection{Time Factor}

It is the percentage availability of the equipment in unit time, which could be an hour or a shift. If the equipment is available 55minutes/hour, and 7 hours in a shift of 8 hours, then it is considered as favorable situation. Under the average condition, availability of 50minutes/hour is common but when if falls to 40 minutes/hour or below it, the condition is considered as unfavorable. The value of this

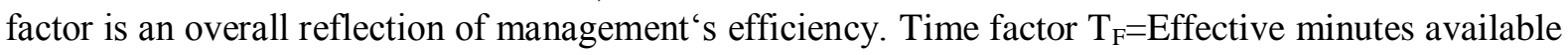
every hour/60

Table2.2. Parameters for Choosing Time Factor

\begin{tabular}{|c|c|c|c|c|}
\hline & \multicolumn{2}{|c|}{ Spot Time(min) } & \multicolumn{2}{c|}{ Dump Time(min) } \\
\hline CONDITIONS & TRUCKS & TRAILERS & TRUCKS & TRAILERS \\
\hline Favorable & 0.15 & 0.15 & 1.0 & 0.3 \\
\hline Average & 0.30 & 0.50 & $1 . .3$ & 0.6 \\
\hline Unfavorable & 0.50 & 1.00 & 1.8 & 1.5 \\
\hline
\end{tabular}

(Source: Anon, 1981)

\subsubsection{Operational Factor $(O F)$}

This is a reflection of working conditions that include layout, matching equipment meant for loading (mucking), transportation, crushing, etc. This also takes into account the services in terms of lighting, ventilation (comports), heat, humidity or any other factor that affects the performance of the equipment, including the operator's efficiency. To apply corrections, usual guideline is mentioned below.

Table2.3. Parameter for selection Operational Factor

\begin{tabular}{|c|c|}
\hline Condition & Correction\% \\
\hline Favorable & 80 \\
\hline Average & 70 \\
\hline Unfavorable & 60 and below \\
\hline
\end{tabular}

Source: Anon [10] 


\subsubsection{Bucket Fill Factor (BF)}

It is the percentage of rated bucket capacity $\left(\mathrm{m}^{3}\right)$ to the one which will actually be delivered in a working cycle. It is based on the degree of fragmentation, or size of material to be filled in, and also bucket teeth or replaceable cutting edge or lip. Given below are the guidelines proposed by the caterpillar in $\mathrm{m}^{3}$.

To select the bucket size from the table (supplied by the manufacturer such as the Table 2.4), use the higher value (of the production range given in the table) if expected fragmentation is good, and low if the value is to be of average rank.

Table2.4. Parameters for choosing Bucket Capacity

\begin{tabular}{|c|c|}
\hline Materials & Fill Factor $(\%)$ \\
\hline \multicolumn{2}{|c|}{ Loose Material Fill Factor } \\
\hline Mixed Moist Aggregates & $95-100 \%$ \\
\hline Uniform Aggregates up to $3 \mathrm{~mm}\left(1 / 8^{\prime \prime}\right)$ & $95-100$ \\
\hline $3 \mathrm{~mm}-9 \mathrm{~mm}(1 / 8 "-3 / 8 ”)$ & $90-95$ \\
\hline $12 \mathrm{~mm}-20 \mathrm{~mm}\left(1 / 2 "{ }^{\prime \prime}-3 / 4 "\right)$ & $85-90$ \\
\hline $24 \mathrm{~mm}(1 ")$ and over & $85-90$ \\
\hline \multicolumn{2}{|c|}{ Blasted Rock } \\
\hline Well Blasted & $80-95 \%$ \\
\hline Average Blasted & $75-90$ \\
\hline Poorly Blasted & $60-75$ \\
\hline \multicolumn{2}{|c|}{ Other } \\
\hline Rock Dirt Mixtures & $100-120 \%$ \\
\hline Moist Loam & $100-110$ \\
\hline Soil, Boulders, Roots & $80-100$ \\
\hline Cemented Materials & $85-95$ \\
\hline \multicolumn{2}{|c|}{ Factors to be Considered } \\
\hline Favorable & 20 \\
\hline Average & 90 \\
\hline Unfavorable & 60 \\
\hline
\end{tabular}

Source: Anon [10]

Note: Loader bucket fill factors are affected by bucket penetration, breakout force, rack-back angle, bucket profile and ground engaging tools such as bucket teeth or bolt-on replaceable cutting edges.

\section{METHODOLOGY}

\subsection{Collection of Data}

The following data were collected from the site of the quarry (HHL Nigeria limited, Ogun State):

Table3.1. Data Collected from the site

\begin{tabular}{|c|c|}
\hline Required production capacity & 10000 tons \\
\hline Operating period & $8 \mathrm{~h} . \mathrm{ft} /$ day \\
\hline Material condition & Well blasted granite \\
\hline Operating condition & Favorable \\
\hline Effective working time per hour & $50 \mathrm{~min}$ \\
\hline Working hours per day & 8 hours including 1 hour rest \\
\hline Break & 1.3 \\
\hline Cycle Time & $15 \mathrm{~min}$ \\
\hline Spotting condition & $0.5 \mathrm{~min}$ \\
\hline
\end{tabular}

\subsection{Equipment Available and other Working Parameters at the Site}

Table3.2. Equipment available at the HHL Nig. Limited

\begin{tabular}{|l|l|}
\hline Required production capacity & 10,000 tons \\
\hline Operating period & One shift per day \\
\hline Material condition & Well blasted granite \\
\hline Operating condition & Favorable \\
\hline Effective working time per hour & 50 min \\
\hline
\end{tabular}




\begin{tabular}{|l|l|}
\hline \multicolumn{2}{|l|}{} \\
\hline Working hour per day & 8 hours including 1 hour break time \\
\hline Relative weight of granite & 1.3 \\
\hline Cycle time & $15 \mathrm{mins}$ \\
\hline Spotting time & $0.5 \mathrm{~min}$ \\
\hline Number of truck & $4(55 \mathrm{tons})$ \\
\hline Number of shovel excavator & One $\left(15 \mathrm{yd}^{3}\right)$ bucket \\
\hline
\end{tabular}

\subsection{Calculation of the Loading and Haulage Operation}

Loading Time $\left(\mathrm{T}_{\mathrm{L}}\right)$

$$
\begin{aligned}
& =\frac{60 \times \text { Tcap }}{\text { Actual shovel output rate }} \\
& =\frac{60 \times 55}{1482} \\
& =\frac{3300}{1482}
\end{aligned}
$$

Loading time $\left(\mathrm{T}_{\mathrm{L}}\right)$

$$
=\quad 2.2 \mathrm{~min} / \mathrm{truck}
$$

Spotting time $\left(\mathrm{T}_{\mathrm{S}}\right)$

$=0.5$

Loading and spotting Time

$$
=\quad(2.2+0.5) \mathrm{min}
$$

$$
=2.7 \mathrm{~min}
$$

CYTmin $\leq \mathrm{NT}(\mathrm{Tl}+\mathrm{Ts})$

$15 \min \leq 4(2.7)$

$15 \min \leq 10.8$

But 15 minutes is not less than or equal to 10.8 minutes, therefore the cycle is not satisfactory and the excavator is excessively waiting for the trucks.

Hence, $15 \mathrm{~min}-10.8 \mathrm{~min}=4.2 \mathrm{~min}$.

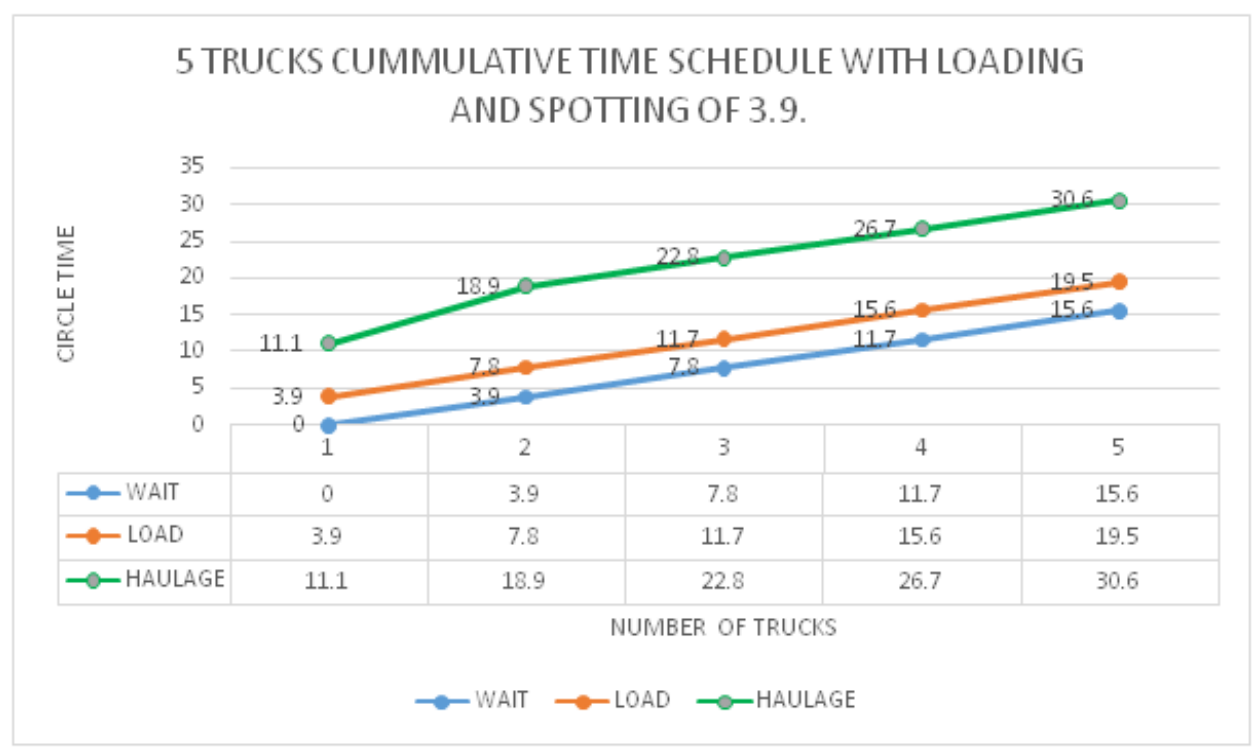

Figure3.2. Graphical representation of 5 trucks with loading and spotting of 3.9

The loader does not wait but the truck will have to queue for 4.5 minutes before they are loaded.

From the result obtained, it can be observed that for the 5 trucks of 85 tons each, hauling of granite at a loading and spotting time of 3.9, the trucks will have to queue for 4.5 minutes to be loaded but the waiting time is not excessive. This complies with the inequality CTYmin $\leq \mathrm{NT}\left(\mathrm{T}_{\mathrm{L}}+\mathrm{T}_{\mathrm{S}}\right)$.

With 4 trucks of loading time of 2.7 in operation cycle of $15 \mathrm{~min}$, the loader will be waiting for the truck which does not conform to the inequality CTYmin $\leq \mathrm{NT}\left(\mathrm{T}_{\mathrm{L}}+\mathrm{T}_{\mathrm{S}}\right)$.

It can be seen that productivity is a complex subject, dependent on a wide range of factor. The type of material mined and the method used to mine it are both fundamental to the range of productivity achievable. 


\section{CONCLUSION}

In conclusion, the quarry (HHL Nigeria limited, Ogun State) has a proven reserve deposit to achieve their production capacity, but improper equipment selection is a hindrance to the required or targeted production output. One excavator and four dump trucks of 15 min cycle time cannot be synchronized.

\section{RECOMMENDATION}

It should be realized that once the conceptual and engineering design and scheduling for the loading and haulage operation have been completed, there should be enough information on size, type and number of loading and haulage equipment which can be synchronized together to meet a targeted production rate within a stipulated working time.

Therefore we recommend that for the company to meet the targeted 10,000 tons of granite per day there is need to use or provide the:

1. Right size of bucket excavator;

2. Right size of trucks;

3. Right number of trucks; and

4. Spares in case of breakdown of equipment.

\section{REFERENCES}

[1] Lizotte Mac. Economics of Mine Transportation. South Western Publication Co. New York. 1988; 514-516

[2] Aghajani B.A. Loading Haulage Equipment Selection in Open Pit Mines Based on Fuzzy-Topzzy Method $4^{\text {th }}$ Edition.2007;1-2.

[3] Çelebi, N. An equipment selection and cost analysis system for open pit coal mines, International Journal of Mining, Reclamation and Environment.1998; 12(4), 181-187. 10.1080/09208118908944042

[4] Caterpillar. Caterpillar Performance Handbook. 34th ed. Caterpillar Inc., Peoria, Illinois, USA.2003

[5] Zhongzhou, L., L. Qining.Erlangian cyclic queueing model for shovel-truck haulage systems. R. Singhal, ed., Mine Planning and Equipment Selection. 1988; 423-428.

[6] Bascetin KofIntroduction to Mine Equipment and Machinery, E and J Inc Ohio.2004;2, 220

[7] Loto and Akande J.M.Loading and Haulage System. SME Mining Engineering Handbook. 1998;220

[8] Gray R. E.Mineral Handling System .Gai Consultant Inc. Toronto.2000;24

[9] Martins F.K. Excavation of Material and S Alloys and Mineral Corp, Victoria 1982; 45

[10] Anon A.Front End Loader Bucket Rating Society of Automotive Engineers Year Book New York.1987;1020.

Citation: A. O. Owolabi, (2019)" Loading and Haulage Equipment Selection for Optimum Production in a Granite Quarry, International Journal of Mining Science (IJMS), 5(2), pp.35-40, DOI: http://dx.doi.org/10.20431/2454-9460.0502004

Copyright: (ㅇ 2019 Authors. This is an open-access article distributed under the terms of the Creative Commons Attribution License, which permits unrestricted use, distribution, and reproduction in any medium, provided the original author and source are credited 